\title{
Spontaneous and Procedural Plaque Embolisation in Native Coronary Arteries: Pathophysiology, Diagnosis, and Prevention
}

\author{
Giovanni Luigi De Maria, ${ }^{1,2}$ Niket Patel, ${ }^{1}$ George Kassimis, ${ }^{1}$ and Adrian P. Banning ${ }^{1}$ \\ ${ }^{1}$ Oxford Heart Centre, John Radcliffe Hospital, Oxford University Hospitals, Headley Way, Oxford OX39DU, UK \\ ${ }^{2}$ Cardiovascular Medicine Department, Catholic University of the Sacred Heart, 00168 Rome, Italy \\ Correspondence should be addressed to Adrian P. Banning; adrian.banning@ouh.nhs.uk
}

Received 20 October 2013; Accepted 11 November 2013

Academic Editors: J. Alpert and C. N. Aroney

Copyright (c) 2013 Giovanni Luigi De Maria et al. This is an open access article distributed under the Creative Commons Attribution License, which permits unrestricted use, distribution, and reproduction in any medium, provided the original work is properly cited.

\begin{abstract}
The detachment of atherothrombotic material from the atherosclerotic coronary plaque and downstream embolisation is an underrecognized phenomenon and it causes different degrees of impairment of the coronary microcirculation. During treatment of obstructive atherosclerotic plaque by percutaneous coronary intervention (PCI) distal embolisation (DE) is considered to be inevitable and it is associated with potential clinical and prognostic implications. This review aims to assess the main aspects of both spontaneous and procedural DE, analyze their different pathophysiology, provide specific insights on the main diagnostic tools for their identification, and finally focus on the main strategies for their treatment and prevention.
\end{abstract}

\section{Introduction}

Atherogenesis is the cause of ischemic heart disease and knowledge about its pathophysiology is progressively increasing. Progression of plaque within a vessel is not merely a consequence of cholesterol accumulation but a dynamic process related to a complex interaction of several risk factors [1]. Intermittent plaque erosion and healing are probably a common event but clinically occult unless protuberant thrombus either dislodges causing flow disturbance downstream or plaque volume increases during healing reducing the luminal volume. This reduced luminal volume may be too small and produces myocardial ischemia in the dependant territory during exertion, manifesting clinically as anginal chest pain.

Treatment of obstructive atheroma by coronary balloon angioplasty was originally described by Gruentzig in 1977. Since then progressive and remarkable innovations in techniques and materials have made percutaneous coronary intervention (PCI) a cornerstone for the treatment of obstructive coronary artery disease (CAD) in many clinical settings [2].
However, achievement of epicardial coronary artery patency does not always translate into a complete and effective myocardial perfusion [3]. This phenomenon known as no reflow (NR) is caused by functional and mechanical impairment of coronary microcirculation and can be described as a condition of "open artery with closed myocardium" (Figure 1).

Individual susceptibility, ischemic-reperfusion, injury and distal embolisation (DE) are the main mechanisms leading to NR [4]. Among these three factors, DE of atherothrombotic debris downstream the coronary circulation with consequent microvascular obstruction (MVO) is the most relevant to the procedure of PCI. Its occurrence may prelude to a failure in restoring the normal myocardial blood flow with relevant clinical and prognostic implications $[5,6]$. That is why understanding and preventing DE remain important for all clinicians and not just for interventional cardiologists.

This review article aims to shed light on this complex phenomenon, providing insights about the pathophysiology of $\mathrm{DE}$ and the available methods to detect and prevent it. 


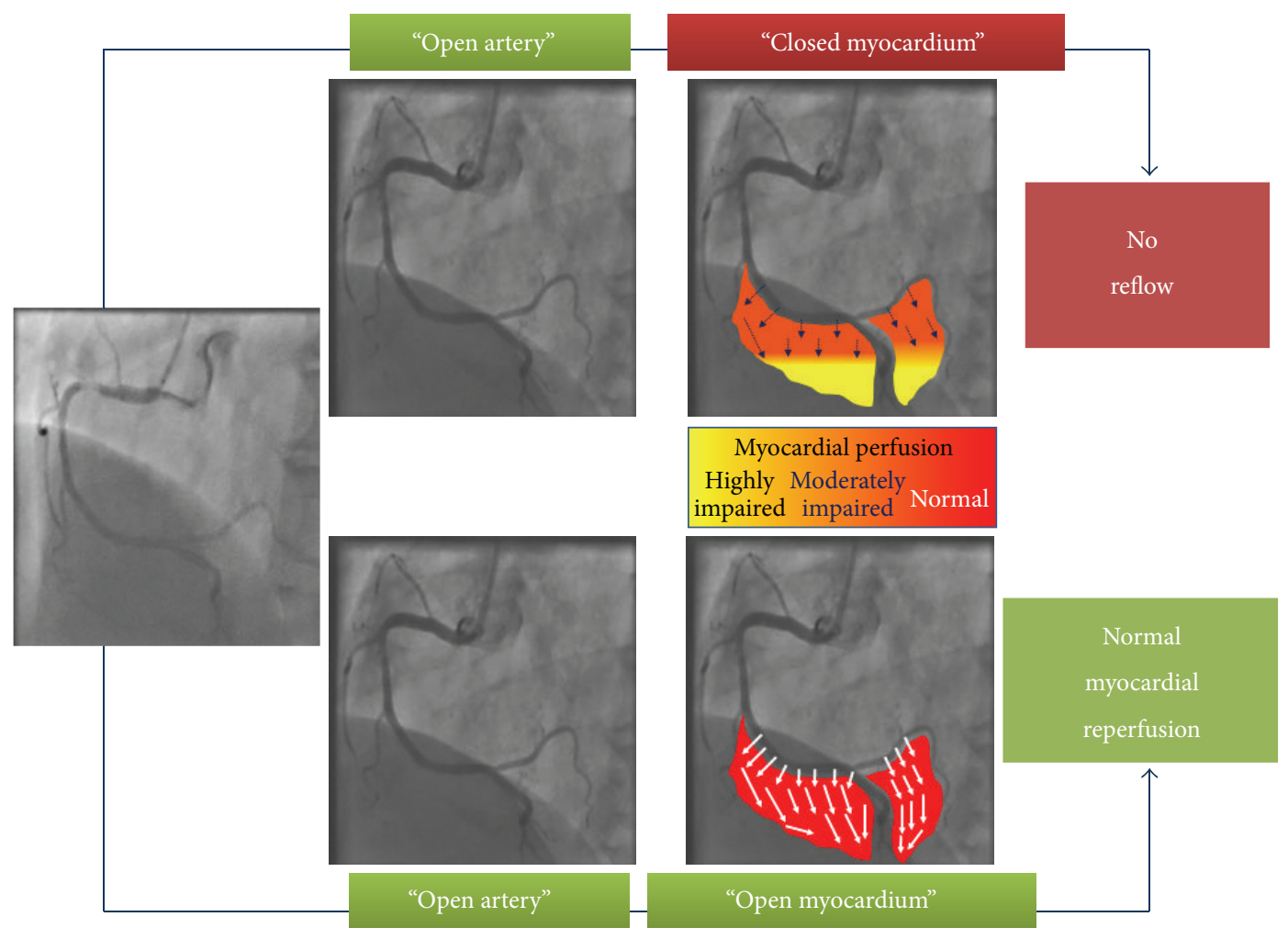

FIGURE 1: No reflow versus normal myocardial perfusion after revascularization.

\section{Distal Embolisation Definition and Pathophysiology}

The term "distal embolisation" refers to the detachment of athero or atherothrombotic fragments from the atherosclerotic plaque and their dislodgement downstream the peripheral portion of the coronary tree. This leads to the occlusion of coronary microcirculation with consequent ongoing myocardial ischemia and necrosis. Compared to classical occlusion of an epicardial segment, DE produces patchy microinfarcts in the area at risk [7], with different degrees of myocardial injury [8].

DE was described for the first time in human in the 1980s by Falk and Davies in two series of patients with sudden death due to coronary thrombosis $[9,10]$. The two groups reported that most of the thrombi had a layered structure, with thrombus material of different age. Intermittent thrombus fragmentation, with peripheral embolisation causing microembolic occlusion of small intramyocardial arteries associated with microinfarcts, was described in $73 \%$ of the cases $[9,10]$.

The interest in DE has been renewed after the development of PCI in which DE is related to balloon dilation or stent deployment. This allows labelling DE as "spontaneous" and "procedural" (Figure 2). Main differences between spontaneous and procedural DE in terms of pathophysiology and diagnostic and therapeutic tools are summarized in Table 1.
2.1. Spontaneous Distal Embolisation. Spontaneous DE is a phenomenon typically observed in ACS patients. It is strictly related to the pathophysiology underlying plaque instability, which is a progressive process going on for several days before the abrupt occlusion of the epicardial coronary artery. Late stage thrombi ( $>7$ days), indeed, have been found in $69 \%$ of culprit plaques [11]. In this evolving phenomenon in which thrombosis and endogenous fibrinolysis take place simultaneously, thrombotic fragments from the growing up thrombus can be spontaneously dislodged and pushed downstream [8].

Broadly, spontaneous DE can be considered to be universal in coronary artery disease (CAD) and is a major component in processes accounting for ACS pathophysiology [7].

In terms of embolisate dimension, both macro- and microembolisation contribute to spontaneous DE. Macroembolisation refers to dislodgement of fragments with a diameter greater than $100 \mu \mathrm{m}$, a cut-off derived from distal filter studies [8], and it consists of atherosclerotic fragments, fibrous and hyaline material, and mainly thrombotic debris [12].

Microembolisation refers to embolised debris with a diameter below $100 \mu \mathrm{m}$. Platelet-platelets aggregates, neutrophils-platelets aggregates, monocytes-platelets aggregates [13], microthrombi [14], amorphous material [15], microparticles [16], cholesterol crystals [17], and leukocytes 


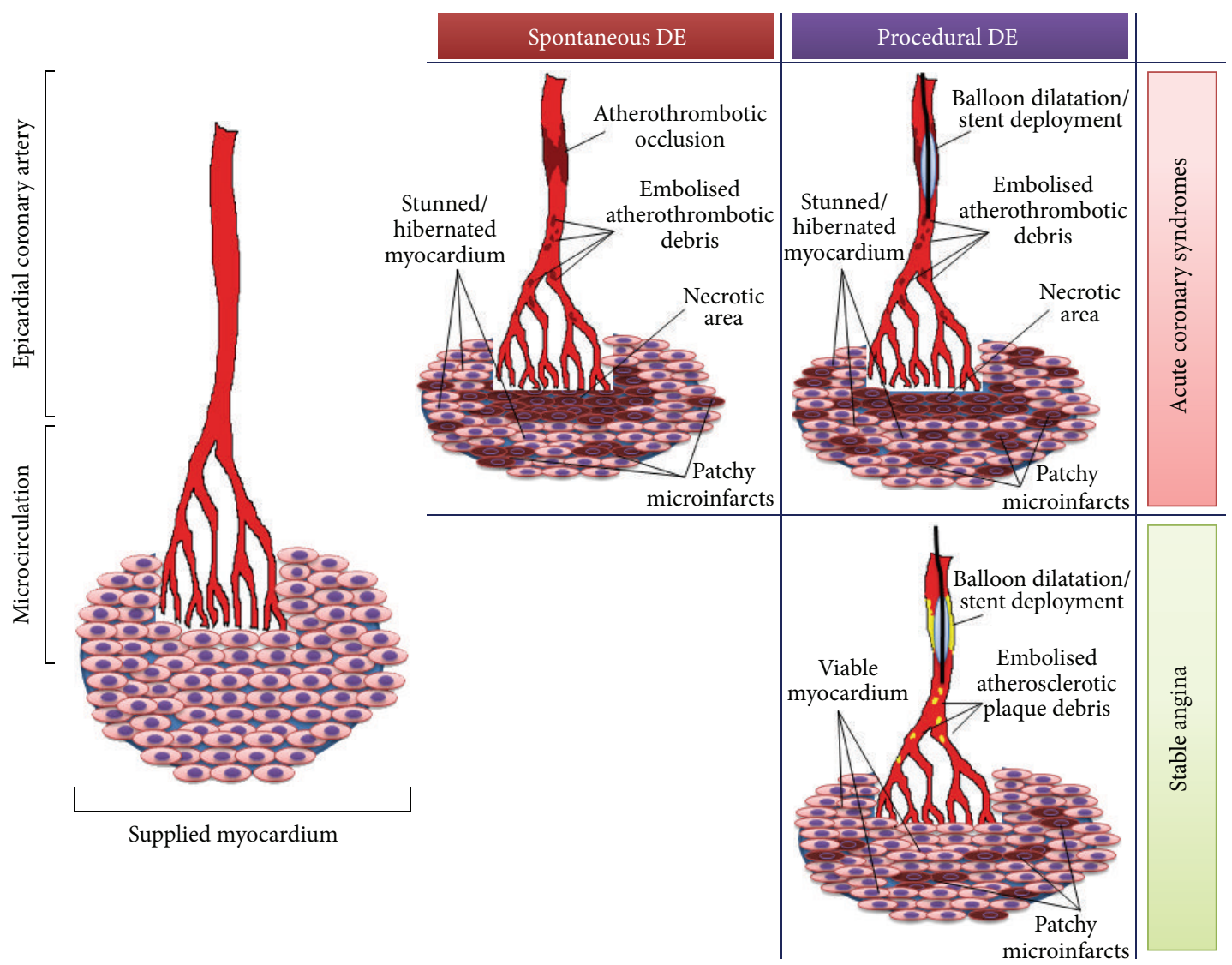

Figure 2: Mechanisms and consequences of "spontaneous" and "procedural" distal embolisation in stable coronary artery disease and in acute coronary syndrome. In spontaneous distal embolisation, occurring only in ACS patients, dislodgement of atherothrombotic debris contributes to enlargement of the area of myocardial injury and microvascular obstruction consequent to epicardial coronary occlusion. This damage is further increased by debris shower during revascularization procedure (procedural distal embolisation). In stable coronary artery disease only procedural distal embolisation occurs, causing patchy microinfarcts.

contribute to microemboli composition [18]. Most of the embolised material is classified as microembolisation [19]. Its consequences extend beyond its merely mechanical occluding effect as the embolic material has thrombogenic, vasoconstrictor, and inflammatory activity [15]. This pharmacological effect is also related to the occurrence of a humoral embolisation, since atherosclerotic plaques, especially if unstable and even ruptured or eroded, are rich in soluble factors able to cause or to worsen the microvascular damage during DE [20-23].

2.2. Procedural Distal Embolisation. Procedural DE is strictly related to PCI procedure and it can occur both in stable and ACS patients. It contributes to the pathophysiologic background of postprocedural myocardial infarction (Type 4a) $[24]$.

Procedural DE recognises risk factors including hypertension [25], diabetes mellitus [26], preexisting renal failure, underlying ACS, lesion length and complexity, thrombus burden, interventions on saphenous vein graft (SVG), direct stenting versus predilation, number and duration of inflations, and rotablation or use of atherectomy [7]. Broadly an average $25 \%$ incidence has been described [7]; however, its occurrence is higher if microembolisation is taken into account beside the angiographically detectable macroembolisation.

Procedural DE composition varies from ACS to stable angina. In the ACS setting, procedural DE components are similar to those of spontaneous DE, mainly consisting of atherothrombotic debris, amorphous hyaline material (macroembolisation), foam cells, cholesterol crystals, platelet-platelet aggregates, leukocytes-platelet aggregates, microparticles, coagulation material (microembolisation) with a high content of tumor necrosis factor alpha, serotonin, thromboxane, and tissue factor (humoral embolisation) [15]. As for spontaneous DE, studies on filters adopted to prevent DE in primary PCI showed that most of procedural DE occurring in the unstable setting consists of microembolisation (22\% particles $<80 \mu \mathrm{m}, 30 \% 80-120 \mu \mathrm{m}, 16 \% 120-250 \mu \mathrm{m}$, $15 \% 250-50 \mu \mathrm{m}$, and $17 \%>500 \mu \mathrm{m})$ [19].

In stable patients procedural DE consists mainly of fibrotic and hyaline material with few cells (foam cells and with a lesser degree also smooth muscular cells, neutrophils, and lymphocytes) [27]. Consequently the biochemical activity of procedural $\mathrm{DE}$ is less potent in stable CAD compared to ACS. 
TABLE 1: Main differences in pathophysiology, diagnosis, and prevention of spontaneous and procedural distal embolisation.

Distal embolisation

Spontaneous

Procedural

\begin{tabular}{|c|c|c|c|}
\hline & \multirow[t]{2}{*}{ Spontaneous } & \multicolumn{2}{|c|}{ Procedural } \\
\hline & & Stable CAD & ACS \\
\hline Clinical setting & ACS & & \\
\hline Embolisate dimension & Macro- and microembolisation & \multicolumn{2}{|c|}{ Macro- and microembolisation } \\
\hline Embolisate composition & $\begin{array}{l}\text { Atherothrombotic fragments } \\
\text { Platelets aggregates } \\
\text { Platelet-monocytes aggregates } \\
\text { Microthrombi } \\
\text { Microparticles } \\
\text { Cholesterol crystal } \\
\text { Amorphous material } \\
\text { Humoral factors }\end{array}$ & $\begin{array}{l}\text { Atherosclerotic fragments } \\
\text { Hyaline material } \\
\text { Fibrous material } \\
\text { Cholesterol crystal }\end{array}$ & $\begin{array}{l}\text { As in spontaneous } \\
\text { DE }\end{array}$ \\
\hline Biochemical activity & $\uparrow \uparrow \uparrow$ & $\uparrow$ & $\uparrow \uparrow \uparrow$ \\
\hline Diagnosis & $\begin{array}{l}\text { True diagnosis only at } \\
\text { postmortem analysis }\end{array}$ & $\begin{array}{l}\text { Laboratory } \\
\uparrow \text { Troponin } \uparrow \mathrm{CK} \text { MB } \\
\text { Imaging } \\
\text { MCE } \\
\text { CMR } \\
\text { Cath-Lab } \\
\text { TIMI flow }\end{array}$ & $\begin{array}{l}\text { Laboratory } \\
\uparrow \text { Troponin } \uparrow \text { CK MB } \\
\text { Imaging } \\
\text { MCE } \\
\text { CMR } \\
\text { Cath-Lab } \\
\text { Intracoronary ECG } \\
\text { ST resolution } \\
\text { TIMI flow and cTFC } \\
\text { MBG }\end{array}$ \\
\hline \multirow[t]{2}{*}{ Therapy and prevention } & $\begin{array}{l}\text { Pharmacologic } \\
\text { Aspirin } \\
\text { Clopidogrel } \\
\text { Prasugrel/ticagrelor } \\
\text { GPIIb/IIIa inhibitors } \\
\text { Statin } \\
\text { Vasodilators } \\
\text { (adenosine/nitroprusside) }\end{array}$ & $\begin{array}{l}\text { Pharmacologic } \\
\text { Aspirin } \\
\text { Clopidogrel } \\
\text { Statin } \\
\text { GPIIb/IIIa* } \\
\text { Vasodilators* }\end{array}$ & $\begin{array}{l}\text { Pharmacologic } \\
\text { As in spontaneous } \\
\text { DE }\end{array}$ \\
\hline & $\begin{array}{l}\text { Mechanical } \\
\text { none }\end{array}$ & $\begin{array}{l}\text { Mechanical (only in SVG) } \\
\text { Distal protection } \\
\text { Balloon-based } \\
\text { Filter-based } \\
\text { Proximal protection }\end{array}$ & $\begin{array}{l}\text { Mechanical } \\
\text { thrombectomy }\end{array}$ \\
\hline
\end{tabular}

${ }^{*}$ Only in complicated PCI.

ACS: acute coronary syndrome; CAD: coronary artery disease; CMR: cardiac magnetic resonance; cTFC: corrected TIMI frame count; DE: distal embolisation; MCE: myocardial contrast echocardiography; MBG: myocardial blush grade; TF: tissue factor; TIMI: thrombolysis in myocardial infarction.

Clear evidence of procedural DE comes from intracoronary Doppler-flow-wire studies which reported firstly a typical reversal systolic flow with a delayed diastolic component and secondly a direct identification of macroemboli appearing as high intensity transient signals on the Doppler spectrum [28]. Further evidence for procedural DE comes from intravascular imaging, describing a direct relationship between plaque volume reduction after PCI with reduced myocardial reperfusion [29] and occurrence of postprocedural myocardial infarction and MVO in both stable and ACS patients [30,31].

2.3. Distal Embolisation Pathophysiology. The relationship between myocardium and DE has been assessed in animal models with injection of inert $40 \mu \mathrm{m}$ microspheres. This infusion resulted in left ventricular impairment with inotropic reserve reduction associated with a compensatory increase of basal coronary blood flow [32] due to adenosine release from ischemic myocytes at the interface between embolised and non embolised myocardium [33]. The increased basal coronary flow caused a blunted vasodilation response, due to occluded small vessels after DE, and led to a significant reduction in coronary flow reserve at the site of embolised myocardium. This is confirmed in human by cardiac magnetic resonance (CMR) analysis [34].

This "contraction-perfusion" mismatch represents a peculiarity of DE.

Both autopsy studies and CMR studies $[35,36]$ confirm that $\mathrm{DE}$ produces patchy microinfarcts responsible for a disproportionate impairment of left ventricular function beyond the actual amount of damaged myocardium [37] which can be quite small after DE (up to $5 \%$ of the perfusion 
territory) [38]. Surprisingly left ventricular impairment is related to the total area of nonperfused myocardium rather than to the volume of necrosis itself [39]. This phenomenon is due to the different mechanism of left ventricular impairment in case of $\mathrm{DE}$, that is, the inflammatory response and tumor necrosis factor release at the interface between embolised and non embolised myocardium [40-43] (Figure 3).

It is likely that procedural DE interaction with microvasculature and myocardium is related to the clinical setting. Indeed in stable patients procedural $\mathrm{DE}$, acting on a viable and "healthy" myocardium, causes an injury pattern close to that observed in animal models, thus accounting for the damage to a small myocardial volume (up to 5\%). In ACS patients, procedural DE amplifies myocardial injury, acting on a severely ischemic and necrotic area which, after epicardial coronary artery occlusion, has suffered from the phenomenon of ischemia-reperfusion injury and previous spontaneous DE [36].

\section{Distal Embolisation: Diagnostic Tools}

Isolated spontaneous DE has been clearly described in postmortem studies on patients who died from sudden death due to coronary thrombosis $[9,10]$. Differentiating between spontaneous and procedural DE in ACS patients is difficult, as these two events occur together in patients undergoing therapeutic PCI with associated procedural DE.

A number of technologies are available to indirectly assess the occurrence of $\mathrm{DE}$, by detecting periprocedural myocardial injury and MVO (Table 1).

3.1. Biomarkers of Myocardial Damage. Troponins are proteins involved in the regulation of cardiac and skeletal muscle contraction, acting by modulating the interaction between actin and myosin. There are three cardiac troponin isoforms, namely, troponin $\mathrm{C}$ (calcium binding), I (inhibitory), and $\mathrm{T}$ (tropomyosin binding), and each is involved in a specific step of calcium mediated actin-myosin interaction [44].

Creatine kinase (CK) is an enzyme involved in the regulation of cellular metabolism, catalysing the conversion of creatine to phosphocreatine thus modulating adenosine triphosphate (ATP) intracellular levels. There are three different isoforms, whereas $\mathrm{CK} \mathrm{MB}$ is the one expressed by myocardium [45].

Increased levels of troponin I or T and of CK MB isoform represent an easy way to detect myocardial injury. Evidence of troponin increase on admission in ACS patients is probably related to spontaneous $\mathrm{DE}$. This is particularly relevant in late presenting patients with older intracoronary thrombi, intermittent epicardial artery occlusion, and showers of microemboli distally to the coronary microcirculation.

There is some debate about the relevance of elevation of biochemical markers of myocardial injury after PCI. Troponin is excellent for risk stratification in ACS and has an advantageous release profile. However, it may be oversensitive for assessing postprocedural myocardial injury, especially since the advent of high-sensitivity troponin assays [46]. At higher levels of troponin elevation a direct relationship between myocardial injury markers and occurrence of PCIrelated myocardial damage has been demonstrated [47] and associated with a poorer prognosis [48]. Conversely, new areas of myocardial necrosis cannot be detected after very small troponin elevations after PCI [49].

$\mathrm{CK} \mathrm{MB}$ elevation has a less complex relationship between myocardial injury and myocardial necrosis after PCI [49]. Indeed, in this regard, in the Cornell Angioplasty Registry a postprocedural troponin elevation in the absence of CK-MB increase was not related to increased in-hospital mortality [50]. Furthermore, the MICASA study showed that a better stratification between myocardial injury and infarction was possible adopting CK-MB and that, paradoxically, all patients undergoing complex PCI would have had a Type $4 \mathrm{a}$ MI diagnosis, according to the postprocedural troponin increase threshold ( $>3$ times the 99th percentile of the upper reference limit) [51, 52]. Interestingly, to obtain the same degree of stratification as $\mathrm{CK}-\mathrm{MB}$, troponin increases thresholds for injury and infarction should be increased to $>12$ times and $>40$ times the 99th percentile of the upper reference limit, respectively [53]. Notably, these values are even beyond those reported by the recent Third Universal Definition of Myocardial Infarction ( $>5$ times the 99th percentile of the upper reference limit) [24].

Moreover, it must be emphasised that postprocedural myocardial injury marker increase may not be entirely related to DE. Two patterns of postprocedural myocardial damage are described by CMR, namely, "distal" and "peristent." Distal is directly related to procedural DE occurrence, whilst peristent reflects the occlusion by the stent of small branch vessels [31].

3.2. Contrast Echocardiography. Based on the infusion of small microbubbles able to remain completely within the microvasculature, myocardial contrast echocardiography (MCE) can detect areas of MVO as region of persistent contrast defect in the territory of the reopened culprit vessel [54]. Moreover, MCE would allow differentiating between procedural $\mathrm{DE}$ in stable $\mathrm{CAD}$ from the combination of both procedural and spontaneous DE occurred in ACS. Indeed, persistent contrast defect regions are typical of ACS patients in which a double embolic shower (spontaneous and procedural) occurs over an already severely compromised area of myocardium [54]. On the contrary, procedural DE in stable CAD patients does not produce contrast defects within the risk area probably because embolic debris does not lead to occlusion of all the arterioles [54].

High spatial and temporal resolution and the relatively low cost are the main advantages of MCE which is however an operator-depending technique [55]. It must be underlined that, at the moment, MCE is not indicated for clinical study but it remains a promising and useful research tool.

3.3. Cardiac Magnetic Resonance Imaging. Contrast-enhanced CMR represents, at the state of art, the gold standard for MVO assessment, with a good sensitivity, superior to MCE [56]. 


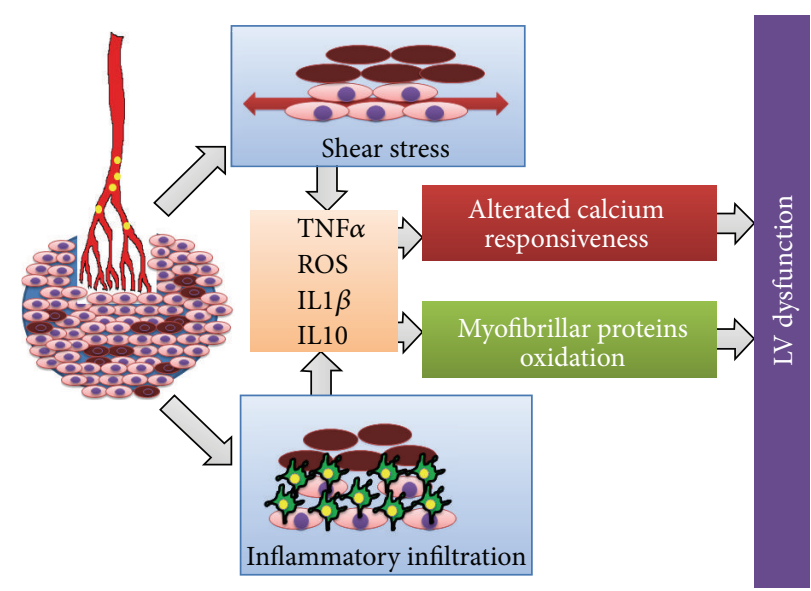

FIGURE 3: Mechanisms leading to left ventricular impairment after distal embolisation. Inflammatory response and shear stress at the interface between embolised and non embolised myocardium trigger the cytokines cascade which leads to myofibrillar proteins oxidation and reduced calcium responsiveness, underlying left ventricular dysfunction after distal embolization.

Two CMR strategies are available to identify MVO. In the first passage method, only after two minutes from contrast injection, MVO appears as hypoenhanced area while the whole myocardium results moderately hyperenhanced. This method is affected by low spatial resolution, reduced left ventricular coverage, and then low diagnostic sensitivity [56].

Higher spatial resolution, increased left ventricular coverage, and the least variability can be obtained with late gadolinium enhanced approach, in which image acquisition, after 10-15 minutes from contrast dye injection, allows detection of MVO as a hypoenhanced area within the hyperenhanced infarct region [57, 58].

Also the timing for CMR scanning has been shown to be relevant since only persistent MVO observed up to one month is really associated with worse regional wall motion and poor prognosis [59].

Notably CMR allows discriminating the mechanism of postprocedural myocardial injury. Indeed, two kinds of late gadolinium enhancement have been described after PCI. A so-called "persistent" pattern, in which the enhanced area is very close to the deployed stent, is caused by poststenting side branch occlusion. In comparison the "distal" pattern is described when the enhanced area is located at least 10 $\mathrm{mm}$ downstream from the stented siste and it is caused by procedural DE [31]. Higher poststenting plaque volume reduction and a significantly reduced myocardial perfusion reserve have been observed in areas of myocardium affected by post-stenting "distal" hyperenhancement [31, 34].

Despite cost, availability issues, and difficult performance in unwell patients, high specificity and sensitivity makes CMR the reference technique for the assessment of acute and chronic consequences of DE.

3.4. In the Cath-Lab. Typical electrocardiographic signs of $\mathrm{DE}$ have been identified in patients undergoing elective PCI and postprocedural myocardial injury defined as troponin increase [60]. While the surface ECG appears to be less predictive of DE, significant ST depression at intracoronary ECG recording presents a $74 \%$ sensitivity and a $95 \%$ specificity in detecting periprocedural troponin increase [60].

Moreover, evaluation of ST resolution at surface ECG has been easily applied to assess the occurrence of MVO and thus indirectly both spontaneous and procedural DE, in STEMI patients undergoing primary PCI [61].

TIMI flow grade [62] and corrected TIMI frame count (cTFC) [63] have been initially adopted as easy angiographic tools to assess postprocedural flow. However, neither TIMI flow grade nor cTFC can provide a direct assessment of tissue perfusion. Myocardial blush grade (MBG) is to date the main angiographic method to assess occurrence of microvascular impairment, related to DE [64]. MBG showed a significant relationship with ST resolution [61], left ventricular function recovery [64], arrhythmogenesis [65], and prognosis [66].

However, the main MBG limitation remains its interobserver variability which can be overcome with a new automated MBG quantification software (Quantitative Blush Evaluator (QuBE)) developed by Zwolle's group [67] and validated with CMR [68].

Intravascular imaging, namely, intravascular ultrasound (IVUS) and optical coherence tomography (OCT), by providing detailed insights into atherosclerotic plaque composition and structure, might be useful in the early identification of prone-to-DE lesions. In this regard, the presence of a necrotic core component derived from virtual histology-IVUS and the morphologic characteristics of plaque derived from grayscale IVUS have been shown to be closely related to procedural DE after PCI $[69,70]$.

Due to its recent introduction in the clinical arena, there is not enough evidence for OCT role in DE diagnosis. However, an additive predictive value of OCT for post-PCI CK-MB elevation in case of IVUS-echo attenuated plaques [71] has been reported. Moreover, a correlation exists between longitudinal plaque lipid pool assessed by OCT and MVO occurrence in STEMI patients [72].

The adoption of the pressure-thermistor-tipped guidewire might provide relevant details about the condition of 
coronary microcirculation. In this regard an increased index of microcirculatory resistance (IMR), defined as the ratio between distal pressure and the inverse of the hyperaemic mean transit time, has been recently related to poor longterm outcomes [73] showing a predictive value for MVO occurrence [74]. Similarly a worsening in IMR has been observed in elective patients who underwent PCI on proneto-DE plaques at virtual histology [75].

Thus, even if their introduction in the clinical arena still needs confirmation from larger clinical trials, both intravascular imaging and coronary functional tests might find an application as diagnostic tools for DE detection and prevention.

\section{Therapy of Distal Embolisation: Is Prevention Better Than Treatment?}

Due to the relevant clinical impact of DE, especially in STEMI patients, several strategies, both pharmacological and mechanical, have been developed to prevent or to reduce the detrimental implications of DE. These strategies, mainly applied in ACS patients, are a useful tool to prevent procedural DE and to treat the consequences of spontaneous DE (Table 1 and Figure 4).

4.1. Spontaneous Distal Embolisation. Pharmacological strategies can be applied to prevent and mainly to limit the myocardial injury in case of spontaneous DE. However, the same pharmacological tools can be adopted to reduce the myocardial damage whenever prevention of procedural DE fails.

4.1.1. Pharmacological Prevention. Three main categories of drugs are available: antiplatelet drugs, statins and vasodilators.

(1) Antiplatelet Drugs. By reducing the thrombotic burden all these agents can limit the occurrence and the amount of both spontaneous and procedural DE.

A direct effect of aspirin on prevention of DE has never been investigated before. However, recent data support a possible contribution of aspirin in DE prevention by reporting a higher thrombus burden [76] and a postprocedural lower coronary flow reserve [77] in ACS patients with documented aspirin resistance.

A direct benefit in terms of periprocedural myonecrosis reduction, and thus in terms of DE prevention, has been shown for P2Y12 receptors antagonists.

The reduction in thrombotic endpoints observed in the PCI-CURE [78], TRITON TIMI 38 [79], and PLATO [80] is the background to think about a role of $\mathrm{P} 2 \mathrm{Y} 12$ receptors inhibitors, respectively, clopidogrel, prasugrel, and ticagrelor, in limiting both spontaneous and procedural DE occurrence.

The strength of antiplatelet activity appears to be doserelated for clopidogrel, as supported by the ARMYDA trials in which higher clopidogrel loading [81] and maintenance dose (600 mg and $150 \mathrm{mg}$, resp.) [82] were associated with a lower incidence of postprocedural myocardial injury. The more favourable pharmacokinetics and pharmacodynamics, instead, underlie the superiority of prasugrel and ticagrelor over clopidogrel observed in TRITON TIMI 38 and PLATO trials, in which a lower occurrence of myocardial infarction in the first days of treatment was likely associated also with an advantage in terms of reduced DE.

Similarly, the analysis of patient-level data from the three CHAMPION trials might support a role for cangrelor, a new fast-acting intravenous antiplatelet agent, in limiting the occurrence and the consequences of DE [83].

Besides P2Y12 receptors antagonists, also GPIIb/IIIa inhibitors may reduce downstream embolisation local generation of thrombus as well vasoactive and chemotactic mediators release from activated platelets [84].

A large core of evidence supports the application of GPIIb/IIIa inhibitors in high-risk PCI with evidence of highly thrombotic burden but a still open debate is about the best timing and the best route for their administration.

After the first evidence of major adverse cardiac events (MACE) reduction with preprocedural administration [85], a clear benefit from GPIIb/IIIa inhibitors upstream adoption has not been confirmed in larger trials $[86,87]$. That is why, currently, guidelines recommend GPIIb/IIIa upstream use (versus in lab-use) only in high-risk patients transferred for primary PCI (IIb level B) [88].

The CICERO trial reported a better MBG and a lower postprocedural myonecrosis using intracoronary administration although no differences in the incidence of MACE were found [89]. The INFUSE AMI trial suggested benefit from intracoronary abciximab as an alternative or on top of manual thrombectomy, with a $11.8 \%$ reduction of infarct size assessed at CMR [90].

A local abciximab delivery strategy by adoption of specifically designed catheters has been purposed. The ongoing COCTAIL II trial will specifically address this issue [91], after that a small study on 50 patients has reported a greater thrombus burden reduction, a lower postprocedural cTFC, and a lower incidence of MACE at one year in patients who underwent local abciximab delivery compared to intracoronary infusion [92].

(2) Statins. Statins exert a stabilizing action on atherosclerotic plaque, protecting from coronary events and leading to a reduction of periprocedural myocardial damage occurrence [93]. Statins efficacy in reducing periprocedural myocardial injury is beyond their lipid-lowering action and is more likely related to the well-known pleiotropic effects [94, 95]. Notably, statins do not prevent DE itself, but they dramatically reduce the impact of embolised debris overt myocardium by attenuating inflammatory consequences of microembolisation. A lower index of myocardial resistance (IMR) in patients pretreated with statins [96] has also been reported.

(3) Vasodilators. Since DE causes both mechanical and functional microvascular impairment, vasodilators would act by dilating the obstructed microcirculation, counteracting the 


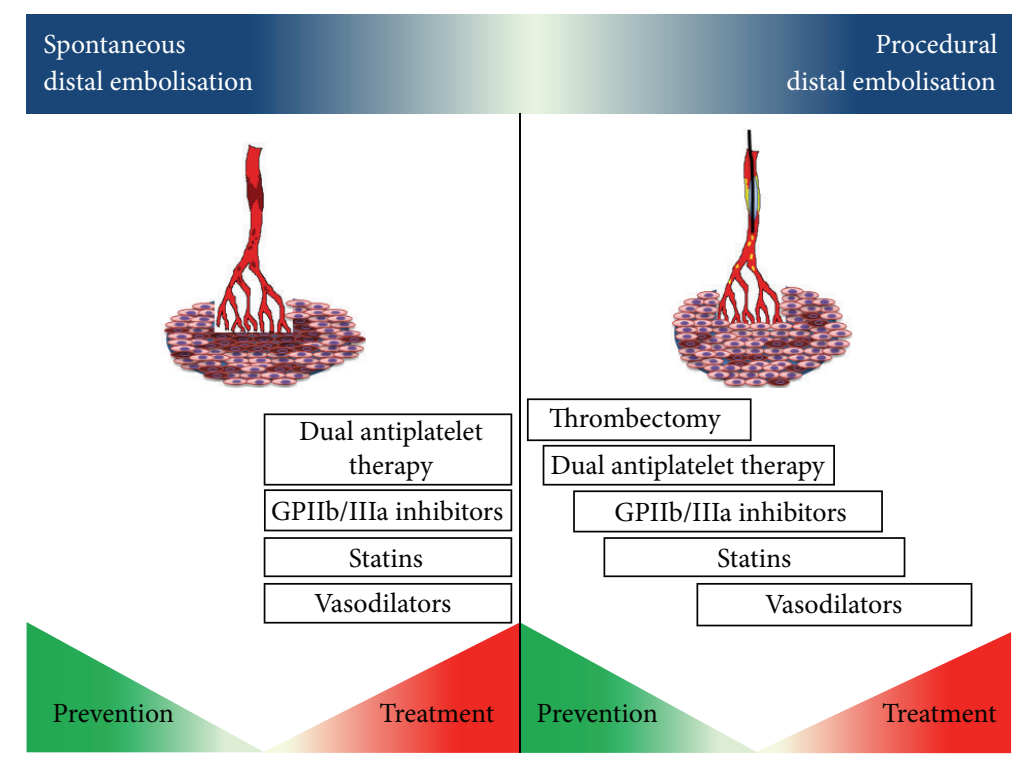

FIgURE 4: Prevention and treatment of spontaneous and procedural distal embolisation. Main mechanical and pharmacological options to treat and prevent distal embolisation in native vessels are reported according to their contribution in dealing with both spontaneous and procedural distal embolisation. Notably since spontaneous distal embolisation has already occurred or is ongoing at admission, pharmacological strategies are adopted with an only "therapeutic" intention in order to reduce the impact of embolised debris on myocardium. On the contrary the same drugs have a double role, preventive and therapeutic, in case of procedural distal embolisation.

vasoconstrictive activity of embolisate. Two main vasodilators agents are currently used in the Cath-Lab to limit the impact of DE: adenosine and sodium nitroprusside.

Adenosine causes vasodilation by binding A2 receptors and inducing adenylate cyclase and platelets nitric oxide synthase activity. At the same time, adenosine exerts an anitinflammatory activity by hampering neutrophils accumulation, limiting free radicals production, damping endothelin1 synthesis, and preventing intracellular $\mathrm{Ca}++$ overload [8]. The first study to document a benefit from adenosine infusion was the AMISTAD I reporting an infarct size reduction in the adenosine group [97]. Even if the AMISTAD-II study broadly failed to detect a significant clinical advantage from intravenous adenosine, however, a benefit of adenosine infusion was reported in those patients treated earlier (within 3-4 hours) and with simultaneous infusion of GPIIB/IIIa [98].

Sodium nitroprusside is a potent endothelium independent vasodilator acting directly on vascular muscle cells, providing a longer maximal coronary hyperemia at a lower dose compared to adenosine [99]. In the only randomized study, nitroprusside showed a better clinical outcome even if not related to myocardial perfusion and coronary flow [100]. The recently published REOPEN AMI trial has shown a net benefit of intracoronary adenosine infusion after thrombectomy compared to nitroprusside and placebo in terms of ST resolution and angiographic detectable MVO [101].

The low nitroprusside dose adopted in the study and the large number of pleiotropic effects exhibited by adenosine are possible explanations for the superiority of intracoronary adenosine in terms of microvascular protection.

Other agents such as nondihydropyridine calcium channel blockers (verapamil and diltiazem), endothelin antagonists, and nicorandil have been purposed to rescue coronary microcirculation from DE, but their use in clinical daily practice is still limited due to lack of strong evidence.

Even if a clear advantage in terms of clinical outcomes has not been confirmed in larger clinical randomized trials, the benefit in terms of infarct size reduction and lower occurrence of MVO supports the current vasodilators adoption, especially adenosine, in case of spontaneous and procedural DE. As for GPIIb/IIIa, also for vasodilators, and again mainly for adenosine, there is a debate about the best time (before/during versus after PCI completion) and the best route of infusion (intracoronary versus intravenous) and ongoing studies will soon address this issue.

Broadly, most of the studies until now have mainly investigated adenosine use after procedure completion; however, since adenosine has a central role in myocardial conditioning [102], it is reasonable that its earlier and prolonged adoption could better prevent the deleterious effects of both spontaneous and procedural DE.

More debated is the issue about the best route of administration. Indeed after the first large clinical trials confirming the effectiveness of intravenous route, intracoronary adenosine administration has been shown to be safe and feasible [103], with a lesser degree of side effects thanks to a lower dosage compared to intravenous systemic infusion [104], and with a high cardioprotective activity [105] and improved tolerance to both spontaneous and procedural DE [106]. However, results from clinical randomized studies adopting intracoronary adenosine infusions are controversial [107, 108]. While a possible explanation could be the lack of agreement on the appropriate intracoronary adenosine dosage able to produce an effective myocardial hyperemia, further investigations are warranted to verify a real superiority of the intracoronary route. 
TABLE 2: Main results from clinical trials about manual thrombus aspiration compared to conventional PCI.

\begin{tabular}{|c|c|c|c|c|c|c|c|}
\hline Study & Year & Device & PTS & Endpoint & FUP & Results & References \\
\hline REMEDIA & 2005 & Diver CE & 99 & $\begin{array}{c}\text { ST resolution } \geq 70 \% \\
\text { MBG } \geq 2 \\
\text { MCE index } \\
\text { WMSI }\end{array}$ & $\begin{array}{c}\mathrm{X} \\
6 \text { months } \\
6 \text { months }\end{array}$ & $\begin{array}{l}\uparrow \\
\uparrow \\
\downarrow \\
\downarrow \\
\end{array}$ & {$[101,106]$} \\
\hline DEAR MI & 2006 & Pronto & 148 & $\begin{array}{c}\text { ST resolution } \geq 70 \% \\
\quad M B G \geq 2 \\
\end{array}$ & $\mathrm{X}$ & $\begin{array}{l}\uparrow \\
\uparrow\end{array}$ & {$[100]$} \\
\hline De Luca et al. & 2006 & Diver CE & 76 & $\begin{array}{c}\text { ST resolution } \geq 70 \% \\
\text { MBG } \geq 2 \\
\text { LV remodeling } \\
\text { MACE }\end{array}$ & $\begin{array}{c}\mathrm{X} \\
6 \text { months } \\
6 \text { months }\end{array}$ & $\begin{array}{l}\uparrow \\
\uparrow \\
\downarrow \\
\leftrightarrow\end{array}$ & {$[102]$} \\
\hline Chevalier et al. & 2008 & Export & 249 & $\begin{array}{l}\text { ST resolution } \geq 70 \% \\
\quad M B G \geq 2 \\
\end{array}$ & $\mathrm{X}$ & $\begin{array}{l}\uparrow \\
\uparrow \\
\end{array}$ & {$[105]$} \\
\hline Chao et al. & 2008 & Export & 74 & $\begin{array}{l}\text { Delta TIMI } \\
\text { Delta MBG } \\
\end{array}$ & $\mathrm{X}$ & $\begin{array}{l}\uparrow \\
\uparrow \\
\end{array}$ & {$[103]$} \\
\hline TAPAS & 2008 & Export & 1071 & $\begin{array}{c}\text { MBG 0/1 } \\
\text { Cardiac death reinfarction }\end{array}$ & $\begin{array}{c}\mathrm{X} \\
1 \text { year }\end{array}$ & $\downarrow$ & {$[98,109]$} \\
\hline Lipiecki et al. & 2009 & Export & 44 & $\begin{array}{l}\text { Infarct size (SPECT) } \\
\text { LV fraction (SPECT) }\end{array}$ & $\mathrm{X}$ & $\begin{array}{l}\leftrightarrow \\
\leftrightarrow\end{array}$ & {$[104]$} \\
\hline Liictro et al. & 2009 & Export & 111 & $\begin{array}{c}\text { ST resolution } \geq 70 \% \\
\text { MBG } \geq 2 \\
\text { MCE index } \\
\text { WMSI }\end{array}$ & $\begin{array}{c}\mathrm{X} \\
6 \text { months }\end{array}$ & $\begin{array}{l}\uparrow \\
\uparrow \\
\downarrow \\
\downarrow\end{array}$ & {$[107]$} \\
\hline EXPIRA & 2009 & Export & 175 & $\begin{array}{c}\text { ST resolution } \geq 70 \% \\
M B G \geq 2 \\
M V O \text { at } C M R\end{array}$ & $\begin{array}{c}\mathrm{X} \\
3 \text { months }\end{array}$ & $\begin{array}{l}\uparrow \\
\uparrow \\
\downarrow\end{array}$ & {$[108]$} \\
\hline PIHRATE & 2010 & Diver CE & 196 & $\begin{array}{c}\text { ST resolution } \geq 70 \% \\
\mathrm{MBG}=3\end{array}$ & $\mathrm{X}$ & $\begin{array}{l}\uparrow \\
\uparrow\end{array}$ & {$[99]$} \\
\hline TASTE & 2013 & $\begin{array}{l}\text { Eliminate } \\
\text { Expert Pronto }\end{array}$ & 7244 & $\begin{array}{l}\text { All-cause mortality } \\
\text { Recurrent MI } \\
\text { Stent thrombosis }\end{array}$ & 30 days & $\begin{array}{l}\leftrightarrow \\
\leftrightarrow \\
\leftrightarrow\end{array}$ & {$[110]$} \\
\hline
\end{tabular}

CMR: cardiac magnetic resonance; FUP: follow-up; LV: left ventricular; MBG: myocardial blush grade; MCE: myocardial contrast echocardiography; MVO: microvascular obstruction; PTS: patients; SPECT: single photon emission computed tomography; WMSI: wall motion score index.

4.2. Procedural Distal Embolisation. While pharmacologic approaches for prevention and treatment of procedural DE overlap with those of spontaneous DE, mechanical prevention is a strategy specifically addressed to prevent the occurrence of procedural DE.

4.2.1. Mechanical Prevention. Balloon/filter protection devices and thrombectomy constitute the equipment for interventional cardiologist dealing with PCI in settings of higher risk of DE, namely, thrombotic lesions and degenerated SVG.

(1) Balloon/Filter Protection Devices. Balloon/filter devices consist of three main types: distal occlusion devices, distal filters, and proximal occlusion devices. Among them, distal filters, consisting of baskets placed distally to lesion, are the most used in clinical practice. Their adoption is however limited to PCI on SVG, since main clinical randomized trials failed to show a real clinical benefit in PCI on native vessels [2]. Embolisation during device deployment, a delay to PCI due to device deployment, and "filter no-reflow" phenomenon occurrence have been claimed as possible mechanisms explaining filters failure in PCI on native vessels $[109,110]$.

(2) Thrombectomy. Aspiration of thrombus material from the coronary lumen is the principle underlying thrombectomy. By providing thrombus debulking, thrombectomy significantly reduces the risk of procedural DE in highly thrombotic lesions and it could also account for a lower probability of spontaneous DE in case of STEMI patients treated with a "lone thrombus aspiration" approach (e.g., thrombus aspiration without stenting) [111].

This tool for DE prevention has currently a IIa indication according to European guidelines in STEMI patients [88]. After the negative result of the TATORT-NSTEMI trials [112], the ongoing TAPAS II [113] will clarify a potential role for thrombectomy also in NSTE-ACS with evidence of high thrombotic burden.

Two main kinds of thrombectomy devices are available at the moment: manual and mechanical. In manual thrombectomy devices, thrombus aspiration is obtained by application of a suction force exerted by the operator. In mechanical 
devices, aspirating force is produced by specific device related mechanisms.

Greater profiles, lower flexibility, and a steeper learning curve have been advocated as the main weak points of mechanical devices. Only two randomized trials have directly compared manual versus mechanical aspiration and both reported no differences between the two approaches in terms of MACE, highlighting however a higher rate of successful deployment of the manual thrombectomy device compared to the mechanical one $[114,115]$. These data have also been independently confirmed in two meta-analyses $[116,117]$.

Recently, the interest for manual thrombectomy has progressively increased. After the first studies ascertaining its benefit in terms of myocardial reperfusion (assessed by ST resolution, MBG [118-125]), MCE [126, 127], and CMR [128] (Table 2), specific randomized clinical trials were needed to confirm its real clinical value.

Even if not designed to address this issue, the TAPAS was the first large study enrolling up to 1071 STEMI patients, reporting not only a better myocardial reperfusion in thrombectomy group [118], but also a reduced cardiac mortality and a lower MACE rate at one-year follow-up [129].

These results, however, have been recently debated in the TASTE trial which failed to find significant differences in terms of mortality, recurrent myocardial infarction, and stent thrombosis at thirty-day follow-up between manual thrombectomy group and controls [130]. The study has the merit to be the first, large (up to 7244 patients) trial designed to address the issue of clinical impact of manual thrombectomy. However, it must be underlined that the thirty-day follow-up could have been too short to assess a real benefit in terms of mortality and occurrence of left ventricular failure related to unfavourable remodeling. Moreover, final results might have been hampered by excluding high-risk patients (those who might have had a real benefit from thrombus aspiration). This apparent "draw" between TAPAS and TASTE studies might be solved after the conclusion of the large ongoing TOTAL trial (ClinicalTrials.gov number NCT01149044).

However, the TASTE trial could indirectly suggest that thrombectomy might really make the difference in specific settings featured by a higher risk of DE such as in patients with large thrombotic burden [131], extended myocardial area at risk [132], and prolonged time to treatment [133].

Finally the results from TASTE trial and TROFI study [134], which failed to detect a significant difference in terms of flow area and stent area between thrombectomy group and control group, might open the door to novel thrombus aspiration devices. ASPIRE aspiration systems, able to produce and to modulate higher aspiration forces, combined with largerlumen catheters (MAX aspiration catheters), are actually under investigation and at the moment they have obtained FDA approval for application in peripheral vasculature [135].

\section{Conclusions}

$\mathrm{DE}$ needs to be considered in the pathophysiology of CAD and it represents a key event during PCI. Spontaneous and procedural $\mathrm{DE}$ can both lead to myocardial injury but the main clinical implications are in PCI and in STEMI patients. Several diagnostic tools are available to detect myocardial injury following DE and progress in intravascular imaging and functional intracoronary tests will be helpful in early detection of DE occurrence and upstream identification of those anatomical settings at higher risk of DE.

Thrombus aspiration, GPIIb/IIIa adoption, dual antiplatelet therapy, and intensive statin treatment are recommended to limit the impact of both spontaneous and procedural DE.

$\begin{array}{ll}\text { Abbreviations } \\ \text { ACS: } & \text { Acute coronary syndrome } \\ \text { CAD: } & \text { Coronary artery disease } \\ \text { CMR: } & \text { Cardiac magnetic resonance } \\ \text { DE: } & \text { Distal embolisation } \\ \text { IMR: } & \text { Index of microcirculatory resistance } \\ \text { IVUS: } & \text { Intravascular ultrasound } \\ \text { MACE: } & \text { Major cardiovascular event } \\ \text { MBG: } & \text { Myocardial blush grade } \\ \text { MCE: } & \text { Myocardial contrast echocardiography } \\ \text { MI: } & \text { Myocardial infarction } \\ \text { MVO: } & \text { Microvascular obstruction } \\ \text { NR: } & \text { No reflow } \\ \text { NSTEMI: Non-ST elevation myocardial infarction } \\ \text { OCT: } & \text { Optical coherence tomography } \\ \text { PCI: } & \text { Percutaneous coronary intervention } \\ \text { STEMI: } & \text { ST elevation myocardial infarction. }\end{array}$

\section{Conflict of Interests}

The authors declare that there is no conflict of interests.

\section{References}

[1] P. Libby and P. Theroux, "Pathophysiology of coronary artery disease," Circulation, vol. 111, no. 25, pp. 3481-3488, 2005.

[2] P. Kolh, W. Wijns, N. Danchin et al., "Guidelines on myocardial revascularization," European Journal of Cardio-Thoracic Surgery, vol. 38, no. 1, pp. 2501-2555, 2010.

[3] S. H. Rezkalla and R. A. Kloner, "No-reflow phenomenon," Circulation, vol. 105, no. 5, pp. 656-662, 2002.

[4] G. Niccoli, F. Burzotta, L. Galiuto, and F. Crea, "Myocardial no-reflow in humans," Journal of the American College of Cardiology, vol. 54, no. 4, pp. 281-292, 2009.

[5] K. C. Wu, E. A. Zerhouni, R. M. Judd et al., "Prognostic significance of microvascular obstruction by magnetic resonance imaging in patients with acute myocardial infarction," Circulation, vol. 97, no. 8, pp. 765-772, 1998.

[6] J. P. S. Henriques, F. Zijlstra, J. P. Ottervanger et al., "Incidence and clinical significance of distal embolization during primary angioplasty for acute myocardial infarction," European Heart Journal, vol. 23, no. 14, pp. 1112-1117, 2002.

[7] G. Heusch, P. Kleinbongard, D. Böse et al., "Coronary microembolization: from bedside to bench and back to bedside," Circulation, vol. 120, no. 18, pp. 1822-1836, 2009. 
[8] I. Porto, G. L. De Maria, M. Pieroni, L. Bolognese, and F. Crea, "Mechanisms, prevention and treatment of distal embolization," Current Pharmaceutical Design, vol. 19, pp. 4576-4585, 2013.

[9] E. Falk, "Unstable angina with fatal outcome: dynamic coronary thrombosis leading to infarction and/or sudden death. Autopsy evidence of recurrent mural thrombosis with peripheral embolization culminating in total vascular occlusion," Circulation, vol. 71, no. 4, pp. 699-708, 1985.

[10] M. J. Davies, A. C. Thomas, P. A. Knapman, and J. R. Hangartner, "Intramyocardial platelet aggregation in patients with unstable angina suffering sudden ischemic cardiac death," Circulation, vol. 73, no. 3, pp. 418-427, 1986.

[11] M. C. A. Kramer, S. Z. H. Rittersma, R. J. de Winter et al., "Relationship of thrombus healing to underlying plaque morphology in sudden coronary death," Journal of the American College of Cardiology, vol. 55, no. 2, pp. 122-132, 2010.

[12] R. Chopard, P. Plastaras, J. Jehl et al., "Effect of macroscopicpositive thrombus retrieval during primary percutaneous coronary intervention with thrombus aspiration on myocardial infarct size and microvascular obstruction," American Journal of Cardiology, vol. 111, pp. 159-165, 2013.

[13] A. D. Michelson, M. R. Barnard, L. A. Krueger, C. R. Valeri, and M. I. Furman, "Circulating monocyte-platelet aggregates are a more sensitive marker of in vivo platelet activation than platelet surface P-selectin: studies in baboons, human coronary intervention, and human acute myocardial infarction," Circulation, vol. 104, no. 13, pp. 1533-1537, 2001.

[14] R. S. Schwartz, A. Burke, A. Farb et al., "Microemboli and microvascular obstruction in acute coronary thrombosis and sudden coronary death. Relation to epicardial plaque histopathology," Journal of the American College of Cardiology, vol. 54, no. 23, pp. 2167-2173, 2009.

[15] P. Kleinbongard, T. Konorza, D. Böse et al., "Lessons from human coronary aspirate," Journal of Molecular and Cellular Cardiology, vol. 52, no. 4, pp. 890-896, 2012.

[16] I. Porto, L. M. Biasucci, G. L. De Maria et al., "Intracoronary microparticles and microvascular obstruction in patients with ST elevation myocardial infarction undergoing primary percutaneous intervention," European Heart Journal, vol. 33, pp. 2928-2938, 2012.

[17] N. Gadeela, J. Rubinstein, U. Tamhane et al., "The impact of circulating cholesterol crystals on vasomotor function: implications for no-reflow phenomenon," JACC: Cardiovascular Interventions, vol. 4, no. 5, pp. 521-529, 2011.

[18] J. Silvain, J.-P. Collet, C. Nagaswami et al., "Composition of coronary thrombus in acute myocardial infarction," Journal of the American College of Cardiology, vol. 57, no. 12, pp. 1359-1367, 2011.

[19] U. Limbruno, A. Micheli, M. De Carlo et al., "Mechanical prevention of distal embolization during primary angioplasty: safety, feasibility, and impact on myocardial reperfusion," Circulation, vol. 108, no. 2, pp. 171-176, 2003.

[20] D. Bonderman, A. Teml, J. Jakowitsch et al., "Coronary noreflow is caused by shedding of active tissue factor from dissected atherosclerotic plaque," Blood, vol. 99, no. 8, pp. 27942800, 2002.

[21] P. Kleinbongard, D. Böse, T. Baars et al., "Vasoconstrictor potential of coronary aspirate from patients undergoing stenting of saphenous vein aortocoronary bypass grafts and its pharmacological attenuation," Circulation Research, vol. 108, no. 3, pp. 344-352, 2011.
[22] H. Funayama, S.-E. Ishikawa, Y. Sugawara, N. Kubo, S.-I. Momomura, and M. Kawakami, "Myeloperoxidase may contribute to the no-reflow phenomenon in patients with acute myocardial infarction," International Journal of Cardiology, vol. 139, no. 2, pp. 187-192, 2010.

[23] A. S. Petronio, G. Amoroso, U. Limbruno et al., "Endothelin-1 release from atherosclerotic plaque after percutaneous transluminal coronary angioplasty in stable angina pectoris and singlevessel coronary artery disease," American Journal of Cardiology, vol. 84, no. 9, pp. 1085-1088, 1999.

[24] K. Thygesen, J. S. Alpert, A. S. Jaffe, M. L. Simoons, B. R. Chaitman, and H. D. White, "Third universal definition of myocardial infarction," European Heart Journal, vol. 33, pp. 2551-2567, 2012.

[25] G. De Luca, A. W. van't Hof, K. Huber et al., "Impact of hypertension on distal embolization, myocardial perfusion, and mortality in patients with ST segment elevation myocardial infarction undergoing primary angioplasty," American Journal of Cardiology, vol. 112, pp. 1083-1086, 2013.

[26] G. De Luca, C. M. Gibson, F. Bellandi et al., "Diabetes mellitus is associated with distal embolization, impaired myocardial perfusion, and higher mortality in patients with ST-segment elevation myocardial infarction treated with primary angioplasty and glycoprotein IIb-IIIa inhibitors," Atherosclerosis, vol. 207, no. 1, pp. 181-185, 2009.

[27] E. Grube, U. Gerckens, A. C. Yeung et al., "Prevention of distal embolization during coronary angioplasty in saphenous vein grafts and native vessels using porous filter protection," Circulation, vol. 104, no. 20, pp. 2436-2441, 2001.

[28] P. Bahrmann, H. R. Figulla, M. Wagner, M. Ferrari, A. Voss, and G. S. Werner, "Detection of coronary microembolisation by Doppler ultrasound during percutaneous coronary interventions," Heart, vol. 91, no. 9, pp. 1186-1192, 2005.

[29] J.-I. Kotani, G. S. Mintz, J. Pregowski et al., "Volumetric intravascular ultrasound evidence that distal embolization during acute infarct intervention contributes to inadequate myocardial perfusion grade," American Journal of Cardiology, vol. 92, no. 6, pp. 728-732, 2003.

[30] D. Fukuda, A. Tanaka, K. Shimada, Y. Nishida, T. Kawarabayashi, and J. Yoshikawa, "Predicting angiographic distal embolization following percutaneous coronary intervention in patients with acute myocardial infarction," American Journal of Cardiology, vol. 91, no. 4, pp. 403-407, 2003.

[31] I. Porto, J. B. Selvanayagam, W. J. Van Gaal et al., "Plaque volume and occurrence and location of periprocedural myocardial necrosis after percutaneous coronary intervention: insights from delayed-enhancement magnetic resonance imaging, thrombolysis in myocardial infarction myocardial perfusion grade analysis, and intravascular ultrasound," Circulation, vol. 114, no. 7, pp. 662-669, 2006.

[32] A. Skyschally, R. Schulz, R. Erbel, and G. Heusch, "Reduced coronary and inotropic reserves with coronary microembolization," American Journal of Physiology, vol. 282, no. 2, pp. H611H614, 2002.

[33] M. Hori, M. Inoue, and M. Kitakaze, "Role of adenosine in hyperemic response of coronary blood flow in microembolization," American Journal of Physiology, vol. 250, no. 3, pp. H509H518, 1986.

[34] J. B. Selvanayagam, A. S. H. Cheng, M. Jerosch-Herold et al., "Effect of distal embolization on myocardial perfusion reserve after percutaneous coronary intervention: a quantitative 
magnetic resonance perfusion study," Circulation, vol. 116, no. 13, pp. 1458-1464, 2007.

[35] M. Carlsson, M. Wilson, A. Martin, and M. Saeed, "Myocardial microinfarction after coronary microembolization in swine: MR imaging characterization," Radiology, vol. 250, no. 3, pp. 703-713, 2009.

[36] M. Saeed, S. W. Hetts, L. Do, and M. W. Wilson, "Coronary microemboli effects in preexisting acute infarcts in a swine model: cardiac MR imaging indices, injury biomarkers, and histopathologic assessment," Radiology, vol. 268, pp. 98-108, 2013.

[37] M. Carlsson, A. J. Martin, P. C. Ursell, D. Saloner, and M. Saeed, "Magnetic resonance imaging quantification of left ventricular dysfunction following coronary microembolization," Magnetic Resonance in Medicine, vol. 61, no. 3, pp. 595-602, 2009.

[38] K. Nassenstein, F. Breuckmann, C. Bucher et al., "How much myocardial damage is necessary to enable detection of focal late gadolinium enhancement at cardiac MR imaging?" Radiology, vol. 249, no. 3, pp. 829-835, 2008.

[39] N. M. Malyar, L. O. Lerman, M. Gössl, P. E. Beighley, and E. L. Ritman, "Relation of nonperfused myocardial volume and surface area to left ventricular performance in coronary microembolization," Circulation, vol. 110, no. 14, pp. 1946-1952, 2004.

[40] H. Dörge, R. Schulz, S. Belosjorow et al., "Coronary microembolization: the role of TNF- $\alpha$ in contractile dysfunction," Journal of Molecular and Cellular Cardiology, vol. 34, no. 1, pp. 51-62, 2002.

[41] A. Skyschally, P. Gres, S. Hoffmann et al., "Bidirectional role of tumor necrosis factor- $\alpha$ in coronary microembolization: progressive contractile dysfunction versus delayed protection against infarction," Circulation Research, vol. 100, no. 1, pp. 140146, 2007.

[42] M. Thielmann, H. Dörge, C. Martin et al., "Myocardial dysfunction with coronary microembolization: signal transduction through a sequence of nitric oxide, tumor necrosis factor- $\alpha$, and sphingosine," Circulation Research, vol. 90, no. 7, pp. 807-813, 2002.

[43] L. Li, X. Zhao, Y. Lu, W. Huang, and W. Wen, "Altered expression of pro- and anti-inflammatory cytokines is associated with reduced cardiac function in rats following coronary microembolization," Molecular and Cellular Biochemistry, vol. 342, no. 1-2, pp. 183-190, 2010.

[44] M. S. Parmacek and J. M. Leiden, "Structure, function, and regulation of troponin C," Circulation, vol. 84, no. 3, pp. 9911003, 1991.

[45] V. Loria, I. Dato, G. L. De Maria, and L. M. Biasucci, "Markers of acute coronary syndrome in emergency room," Minerva Medica, vol. 99, no. 5, pp. 497-509, 2008.

[46] F. Cuculi, C. C. S. Lim, and A. P. Banning, "Periprocedural myocardial injury during elective percutaneous coronary intervention: is it important and how can it be prevented?" Heart, vol. 96, no. 10, pp. 736-740, 2010.

[47] J. B. Selvanayagam, I. Porto, K. Channon et al., "Troponin elevation after percutaneous coronary intervention directly represents the extent of irreversible myocardial injury: insights from cardiovascular magnetic resonance imaging," Circulation, vol. 111, no. 8, pp. 1027-1032, 2005.

[48] K. Rahimi, A. P. Banning, A. S. H. Cheng et al., "Prognostic value of coronary revascularisation-related myocardial injury: a cardiac magnetic resonance imaging study," Heart, vol. 95, no. 23, pp. 1937-1943, 2009.
[49] W. J. van Gaal and A. P. Banning, "Diagnosing peri-procedural myocardial injury following percutaneous coronary intervention: replacing confusion with consensus," Heart, vol. 98, pp. 1473-1475, 2012.

[50] D. N. Feldman, R. M. Minutello, G. Bergman, I. Moussa, and S. C. Wong, "Relation of troponin I levels following nonemergent percutaneous coronary intervention to short- and long-term outcomes," American Journal of Cardiology, vol. 104, no. 9, pp. 1210-1215, 2009.

[51] K. Thygesen, J. S. Alpert, and H. D. White, "Universal definition of myocardial infarction," European Heart Journal, vol. 28, no. 20, pp. 2525-2538, 2007.

[52] W. J. van Gaal, J. R. Arnold, L. Testa et al., "Myocardial Injury following Coronary Artery Surgery versus Angioplasty (MICASA): a randomised trial using biochemical markers and cardiac magnetic resonance imaging," EuroIntervention, vol. 6, no. 6, pp. 703-710, 2011.

[53] C. C. S. Lim, W. J. Van Gaal, L. Testa et al., "With the "universal definition," measurement of creatine kinase-myocardial band rather than troponin allows more accurate diagnosis of periprocedural necrosis and infarction after coronary intervention," Journal of the American College of Cardiology, vol. 57, no. 6, pp. 653-661, 2011.

[54] H. Ito, "Myocardial contrast echocardiography after myocardial infarction," Current Cardiology Reports, vol. 14, pp. 350-358, 2012.

[55] I. Porto, C. Hamilton-Craig, M. Brancati, F. Burzotta, L. Galiuto, and F. Crea, "Angiographic assessment of microvascular perfusion-myocardial blush in clinical practice," American Heart Journal, vol. 160, no. 6, pp. 1015-1022, 2010.

[56] K. C. Wu, "CMR of microvascular obstruction and hemorrhage in myocardial infarction," Journal of Cardiovascular Magnetic Resonance, vol. 14, p. 68, 2012.

[57] D. S. Fieno, R. J. Kim, E.-L. Chen, J. W. Lomasney, F. J. Klocke, and R. M. Judd, "Contrast-enhanced magnetic resonance imaging of myocardium at risk: distinction between reversible and irreversible injury throughout infarct healing," Journal of the American College of Cardiology, vol. 36, no. 6, pp. 1985-1991, 2000.

[58] R. M. Judd, C. H. Lugo-Olivieri, M. Arai et al., "Physiological basis of myocardial contrast enhancement in fast magnetic resonance images of 2-day-old reperfused canine infarcts," Circulation, vol. 92, no. 7, pp. 1902-1910, 1995.

[59] S. Ørn, C. Manhenke, O. J. Greve et al., "Microvascular obstruction is a major determinant of infarct healing and subsequent left ventricular remodelling following primary percutaneous coronary intervention," European Heart Journal, vol. 30, no. 16, pp. 1978-1985, 2009.

[60] V. Balian, M. Galli, C. Marcassa et al., "Intracoronary STsegment shift soon after elective percutaneous coronary intervention accurately predicts periprocedural myocardial injury," Circulation, vol. 114, no. 18, pp. 1948-1954, 2006.

[61] P. Sorajja, B. J. Gersh, C. Costantini et al., "Combined prognostic utility of ST-segment recovery and myocardial blush after primary percutaneous coronary intervention in acute myocardial infarction," European Heart Journal, vol. 26, no. 7, pp. 667-674, 2005.

[62] Investigator TGA, "The effects of tissue plasminogen activator, streptokinase, or both on coronary-artery patency, ventricular function, and survival after acute myocardial infarction. The GUSTO Angiographic Investigators," The New England Journal of Medicine, vol. 329, pp. 1615-1622, 1993. 
[63] C. M. Gibson, C. P. Cannon, W. L. Daley et al., “TIMI frame count: a quantitative method of assessing coronary artery flow," Circulation, vol. 93, no. 5, pp. 879-888, 1996.

[64] A. W. J. van 't Hof, A. Liem, H. Suryapranata, J. C. A. Hoorntje, M.-J. de Boer, and F. Zijlstra, "Angiographic assessment of myocardial reperfusion in patients treated with primary angioplasty for acute myocardial infarction: myocardial blush grade," Circulation, vol. 97, no. 23, pp. 2302-2306, 1998.

[65] C. M. Gibson, Y. B. Pride, J. L. Buros et al., "Association of impaired thrombolysis in myocardial infarction myocardial perfusion grade with ventricular tachycardia and ventricular fibrillation following fibrinolytic therapy for ST-segment elevation myocardial infarction," Journal of the American College of Cardiology, vol. 51, no. 5, pp. 546-551, 2008.

[66] G. Ndrepepa, K. Tiroch, M. Fusaro et al., "5-year prognostic value of no-reflow phenomenon after percutaneous coronary intervention in patients with acute myocardial infarction," Journal of the American College of Cardiology, vol. 55, no. 21, pp. 2383-2389, 2010.

[67] M. Vogelzang, P. J. Vlaar, T. Svilaas, D. Amo, M. W. N. Nijsten, and F. Zijlstra, "Computer-assisted myocardial blush quantification after percutaneous coronary angioplasty for acute myocardial infarction: a substudy from the TAPAS trial," European Heart Journal, vol. 30, no. 5, pp. 594-599, 2009.

[68] I. Porto, C. Hamilton-Craig, G. L. De Maria et al., "Quantitative Blush Evaluator accurately quantifies microvascular dysfunction in patients with ST-elevation myocardial infarction: comparison with cardiovascular magnetic resonance," American Heart Journal, vol. 162, no. 2, pp. 372-e2, 2011.

[69] B. E. Claessen, A. Maehara, M. Fahy, K. Xu, G. W. Stone, and G. S. Mintz, "Plaque composition by intravascular ultrasound and distal embolization after percutaneous coronary intervention," JACC: Cardiovascular Imaging, vol. 5, no. 3, pp. S111-S118, 2012.

[70] J. S. Jang, H. Y. Jin, J. S. Seo et al., "Meta-analysis of plaque composition by intravascular ultrasound and its relation to distal embolization after percutaneous coronary intervention," American Journal of Cardiology, vol. 111, pp. 968-972, 2013.

[71] T. Lee, T. Kakuta, T. Yonetsu et al., "Assessment of echoattenuated plaque by optical coherence tomography and its impact on post-procedural creatine kinase-myocardial band elevation in elective stent implantation," JACC: Cardiovascular Interventions, vol. 4, no. 5, pp. 483-491, 2011.

[72] H. Ikenaga, M. Ishihara, I. Inoue et al., "Longitudinal extent of lipid pool assessed by optical coherence tomography predicts microvascular no-reflow after primary percutaneous coronary intervention for ST-segment elevation myocardial infarction," Journal of Cardiology, vol. 62, pp. 71-76, 2013.

[73] W. F. Fearon, A. F. Low, A. S. Yong et al., "Prognostic value of the Index of Microcirculatory Resistance measured after primary percutaneous coronary intervention," Circulation, vol. 127, no. 24, pp. 2436-2441, 2013.

[74] R. McGeoch, S. Watkins, C. Berry et al., "The index of microcirculatory resistance measured acutely predicts the extent and severity of myocardial infarction in patients with ST-segment elevation myocardial infarction," JACC: Cardiovascular Interventions, vol. 3, no. 7, pp. 715-722, 2010.

[75] R. Yamada, H. Okura, T. Kume et al., "Target lesion thincap fibroatheroma defined by virtual histology intravascular ultrasound affects microvascular injury during percutaneous coronary intervention in patients with angina pectoris," Circulation Journal, vol. 74, no. 8, pp. 1658-1662, 2010.
[76] G. Niccoli, C. Spaziani, M. Marino et al., "Effect of chronic Aspirin therapy on angiographic thrombotic burden in patients admitted for a first ST-elevation myocardial infarction," American Journal of Cardiology, vol. 105, no. 5, pp. 587-591, 2010.

[77] W.-H. Chen, P.-Y. Lee, W. Ng et al., "Relation of aspirin resistance to coronary flow reserve in patients undergoing elective percutaneous coronary Intervention," American Journal of Cardiology, vol. 96, no. 6, pp. 760-763, 2005.

[78] S. R. Mehta, S. Yusuf, R. J. G. Peters et al., "Effects of pretreatment with clopidogrel and aspirin followed by longterm therapy in patients undergoing percutaneous coronary intervention: the PCI-CURE study," The Lancet, vol. 358, no. 9281, pp. 527-533, 2001.

[79] S. D. Wiviott, E. Braunwald, C. H. McCabe et al., "Prasugrel versus clopidogrel in patients with acute coronary syndromes," The New England Journal of Medicine, vol. 357, no. 20, pp. 20012015, 2007.

[80] L. Wallentin, R. C. Becker, A. Budaj et al., "Ticagrelor versus clopidogrel in patients with acute coronary syndromes," The New England Journal of Medicine, vol. 361, no. 11, pp. 1045-1057, 2009.

[81] G. Patti, G. Colonna, V. Pasceri, L. L. Pepe, A. Montinaro, and G. Di Sciascio, "Randomized trial of high loading dose of clopidogrel for reduction of periprocedural myocardial infarction in patients undergoing coronary intervention: results from the ARMYDA-2 (Antiplatelet therapy for Reduction of MYocardial Damage during Angioplasty) Study," Circulation, vol. 111, no. 16, pp. 2099-2106, 2005.

[82] G. Patti, D. Grieco, G. Dicuonzo, V. Pasceri, A. Nusca, and G. Di Sciascio, "High versus standard clopidogrel maintenance dose after percutaneous coronary intervention and effects on platelet inhibition, endothelial function, and inflammation: results of the ARMYDA-150 mg (antiplatelet therapy for reduction of myocardial damage during angioplasty) randomized study," Journal of the American College of Cardiology, vol. 57, no. 7, pp. 771-778, 2011.

[83] P. G. Steg, D. L. Bhatt, C. W. Hamm et al., "Effect of cangrelor on periprocedural outcomes in percutaneous coronary interventions: a pooled analysis of patient-level data," The Lancet, 2013.

[84] H. Kunichika, O. Ben-Yehuda, S. Lafitte, N. Kunichika, B. Peters, and A. N. DeMaria, "Effects of glycoprotein IIb/IIIa inhibition on microvascular flow after coronary reperfusion: a quantitative myocardial contrast echocardiography study," Journal of the American College of Cardiology, vol. 43, no. 2, pp. 276-283, 2004.

[85] J. Gödicke, M. Flather, M. Noc et al., "Early versus periprocedural administration of abciximab for primary angioplasty: a pooled analysis of 6 studies," American Heart Journal, vol. 150, no. 5, pp. 1015-el1, 2005.

[86] S. G. Ellis, M. Tendera, M. A. de Belder et al., "Facilitated PCI in patients with ST-elevation myocardial infarction," The New England Journal of Medicine, vol. 358, no. 21, pp. 2205-2217, 2008.

[87] A. W. van't Hof, J. ten Berg, T. Heestermans et al., "Prehospital initiation of tirofiban in patients with ST-elevation myocardial infarction undergoing primary angioplasty (On-TIME 2): a multicentre, double-blind, randomised controlled trial," The Lancet, vol. 372, no. 9638, pp. 537-546, 2008.

[88] P. G. Steg, S. K. James, D. Atar et al., "ESC guidelines for the management of acute myocardial infarction in patients presenting with ST-segment elevation," European Heart Journal, vol. 33, no. 20, pp. 2569-2619, 2012. 
[89] Y. L. Gu, M. A. Kampinga, W. G. Wieringa et al., "Intracoronary versus intravenous administration of abciximab in patients with ST-segment elevation myocardial infarction undergoing primary percutaneous coronary intervention with thrombus aspiration: the comparison of intracoronary versus intravenous abciximab administration during emergency reperfusion of ST-segment elevation myocardial infarction (CICERO) trial," Circulation, vol. 122, no. 25, pp. 2709-2717, 2010.

[90] G. W. Stone, A. Maehara, B. Witzenbichler et al., "Intracoronary abciximab and aspiration thrombectomy in patients with large anterior myocardial infarction: the INFUSE-AMI randomized trial," Journal of the American Medical Association, vol. 307, no. 17, pp. 1817-1826, 2012.

[91] F. Prati, L. Di Vito, V. Ramazzotti et al., "Randomized trial of standard versus ClearWay-infused abciximab and thrombectomy in myocardial infarction: rationale and design of the COCTAIL II study," Journal of Cardiovascular Medicine, vol. 14, pp. 364-371, 2013.

[92] F. Prati, D. Capodanno, T. Pawlowski et al., "Local delivery versus intracoronary infusion of abciximab in patients with acute coronary syndromes," JACC: Cardiovascular Interventions, vol. 3, no. 9, pp. 928-934, 2010.

[93] G. Patti, C. P. Cannon, S. A. Murphy et al., "Clinical benefit of statin pretreatment in patients undergoing percutaneous coronary intervention: a collaborative patient-level meta-analysis of 13 randomized studies," Circulation, vol. 123, no. 15, pp. 1622$1632,2011$.

[94] G. G. Schwartz, A. G. Olsson, M. D. Ezekowitz et al., "Effects of atorvastatin on early recurrent ischemic events in acute coronary syndromes the MIRACL study: a randomized controlled trial," Journal of the American Medical Association, vol. 285, no. 13, pp. 1711-1718, 2001.

[95] C. M. Gibson, Y. B. Pride, C. P. Hochberg, S. Sloan, M. S. Sabatine, and C. P. Cannon, "Effect of intensive statin therapy on clinical outcomes among patients undergoing percutaneous coronary intervention for acute coronary syndrome. PCIPROVE IT: a PROVE IT-TIMI 22 (Pravastatin or Atorvastatin Evaluation and Infection Therapy-Thrombolysis in Myocardial Infarction 22) Substudy," Journal of the American College of Cardiology, vol. 54, no. 24, pp. 2290-2295, 2009.

[96] K. Fujii, D. Kawasaki, K. Oka et al., "The impact of pravastatin pre-treatment on periprocedural microcirculatory damage in patients undergoing percutaneous coronary intervention," JACC: Cardiovascular Interventions, vol. 4, no. 5, pp. 513-520, 2011.

[97] K. W. Mahaffey, J. A. Puma, N. A. Barbagelata et al., "Adenosine as an adjunct to thrombolytic therapy for acute myocardial infarction-results of a multicenter, randomized, placebocontrolled trial: the acute myocardial infarction STudy of ADenosine (AMISTAD) trial," Journal of the American College of Cardiology, vol. 34, no. 6, pp. 1711-1720, 1999.

[98] A. M. Ross, R. J. Gibbons, G. W. Stone, R. A. Kloner, and R. W. Alexander, "A randomized, double-blinded, placebo-controlled multicenter trial of adenosine as an adjunct to reperfusion in the treatment of acute myocardial infarction (AMISTAD-II)," Journal of the American College of Cardiology, vol. 45, no. 11, pp. 1775-1780, 2005.

[99] W. A. Parham, A. Bouhasin, J. P. Ciaramita, S. Khoukaz, S. C. Herrmann, and M. J. Kern, "Coronary hyperemic dose responses of intracoronary sodium nitroprusside," Circulation, vol. 109, no. 10, pp. 1236-1243, 2004.

[100] G. Amit, C. Cafri, S. Yaroslavtsev et al., "Intracoronary nitroprusside for the prevention of the no-reflow phenomenon after primary percutaneous coronary intervention in acute myocardial infarction. A randomized, double-blind, placebocontrolled clinical trial," American Heart Journal, vol. 152, no. 5, pp. 887.e9-887.e14, 2006.

[101] G. Niccoli, S. Rigattieri, M. R. De Vita et al., "Open-label, randomized, placebo-controlled evaluation of intracoronary adenosine or nitroprusside after thrombus aspiration during primary percutaneous coronary intervention for the prevention of microvascular obstruction in acute myocardial infarction: the REOPEN-AMI study (Intracoronary Nitroprusside Versus Adenosine in Acute Myocardial Infarction)," JACC: Cardiovascular Interventions, vol. 6, pp. 580-589, 2013.

[102] A. R. De Caterina, F. Cuculi, A. P. Banning, and R. K. Kharbanda, "Protecting the heart: biological targets and clinical strategies," Current Pharmaceutical Design, vol. 19, pp. 45294543, 2013.

[103] P. P. Singh, M. Singh, N. Khosla et al., "Safety and efficacy of transradial versus transfemoral percutaneous coronary intervention in acute myocardial infarction: a meta-analysis of randomized trials," Coronary Artery Disease, vol. 23, no. 4, pp. 101-114, 2012.

[104] A. M. Leone, I. Porto, A. R. De Caterina et al., "Maximal hyperemia in the assessment of fractional flow reserve: intracoronary adenosine versus intracoronary sodium nitroprusside versus intravenous adenosine: the NASCI (nitroprussiato versus adenosina nelle stenosi coronariche intermedie) study," JACC: Cardiovascular Interventions, vol. 5, no. 4, pp. 402-408, 2012.

[105] Z.-X. Jin, J.-J. Zhou, M. Xin et al., "Postconditioning the human heart with adenosine in heart valve replacement surgery," Annals of Thoracic Surgery, vol. 83, no. 6, pp. 2066-2072, 2007.

[106] G. Doolub and E. Dall'Armellina, "Intracoronary adenosine versus intravenous adenosine during primary PCI for ST-elevation myocardial infarction: which one offers better outcomes in terms of microvascular obstruction?" ISRN Cardiology, vol. 2013, Article ID 248476, 8 pages, 2013.

[107] M. L. Fokkema, P. J. Vlaar, M. Vogelzang et al., "Effect of highdose intracoronary adenosine administration during primary percutaneous coronary intervention in acute myocardial infarction a randomized controlled trial," Circulation: Cardiovascular Interventions, vol. 2, no. 4, pp. 323-329, 2009.

[108] W. Desmet, J. Bogaert, C. Dubois et al., "High-dose intracoronary adenosine for myocardial salvage in patients with acute ST-segment elevation myocardial infarction," European Heart Journal, vol. 32, no. 7, pp. 867-877, 2011.

[109] L. Mauri, C. Rogers, and D. S. Baim, "Devices for distal protection during percutaneous coronary revascularization," Circulation, vol. 113, no. 22, pp. 2651-2656, 2006.

[110] I. Porto, F. Belloni, G. Niccoli et al., "Filter no-reflow during percutaneous coronary intervention of saphenous vein grafts: incidence, predictors and effect of the type of protection device," EuroIntervention, vol. 7, no. 8, pp. 955-961, 2011.

[111] J. Escaned, M. Echavarria-Pinto, T. Gorgadze et al., "Safety of lone thrombus aspiration without concomitant coronary stenting in selected patients with acute myocardial infarction," EuroIntervention, vol. 8, pp. 1149-1156, 2013.

[112] S. de Waha, I. Eitel, S. Desch et al., "Thrombus Aspiration in ThrOmbus containing culpRiT lesions in Non-ST-Elevation Myocardial Infarction (TATORT-NSTEMI): study protocol for a randomized controlled trial," Trials, vol. 14, p. 110, 2013.

[113] M. A. Kampinga, P. J. Vlaar, M. L. Fokkema, Y. L. Gu, and F. Zijlstra, "Thrombus aspiration during percutaneous coronary 
intervention in acute non-ST-elevation myocardial infarction study (TAPAS II)-study design," Netherlands Heart Journal, vol. 17, no. 11, pp. 409-413, 2009.

[114] M. A. Vink, M. S. Patterson, J. V. Etten et al., "A randomized comparison of manual versus mechanical thrombus removal in primary percutaneous coronary intervention in the treatment of ST-segment elevation myocardial infarction (TREAT-MI)," Catheterization and Cardiovascular Interventions, vol. 78, no. 1, pp. 14-19, 2011.

[115] G. Parodi, R. Valenti, A. Migliorini et al., "Comparison of manual thrombus aspiration with rheolytic thrombectomy in acute myocardial infarction," Circulation: Cardiovascular Interventions, vol. 6, pp. 224-230, 2013.

[116] E. P. Navarese, G. Tarantini, G. Musumeci et al., "Manual vs mechanical thrombectomy during PCI for STEMI: a comprehensive direct and adjusted indirect meta-analysis of randomized trials," American Journal of Cardiovascular Disease, vol. 3, pp. 146-157, 2013.

[117] F. Burzotta, M. De Vita, Y. L. Gu et al., "Clinical impact of thrombectomy in acute ST-elevation myocardial infarction: an individual patient-data pooled analysis of 11 trials," European Heart Journal, vol. 30, no. 18, pp. 2193-2203, 2009.

[118] T. Svilaas, P. J. Vlaar, I. C. van der Horst et al., "Thrombus aspiration during primary percutaneous coronary intervention," The New England Journal of Medicine, vol. 358, no. 6, pp. 557-567, 2008.

[119] D. Dudek, W. Mielecki, F. Burzotta et al., "Thrombus aspiration followed by direct stenting: a novel strategy of primary percutaneous coronary intervention in ST-segment elevation myocardial infarction. Results of the Polish-Italian-Hungarian RAndomized ThrombEctomy Trial (PIHRATE Trial)," American Heart Journal, vol. 160, no. 5, pp. 966-972, 2010.

[120] P. Silva-Orrego, P. Colombo, R. Bigi et al., “Thrombus aspiration before primary angioplasty improves myocardial reperfusion in acute myocardial infarction: the DEAR-MI (Dethrombosis to Enhance Acute Reperfusion in Myocardial Infarction) study," Journal of the American College of Cardiology, vol. 48, no. 8, pp. 1552-1559, 2006.

[121] F. Burzotta, C. Trani, E. Romagnoli et al., "Manual thrombusaspiration improves myocardial reperfusion: the randomized evaluation of the effect of mechanical reduction of distal embolization by thrombus-aspiration in primary and rescue angioplasty (REMEDIA) trial," Journal of the American College of Cardiology, vol. 46, no. 2, pp. 371-376, 2005.

[122] L. De Luca, G. Sardella, C. J. Davidson et al., "Impact of intracoronary aspiration thrombectomy during primary angioplasty on left ventricular remodelling in patients with anterior ST elevation myocardial infarction," Heart, vol. 92, no. 7, pp. 951957, 2006.

[123] C.-L. Chao, C.-S. Hung, Y.-H. Lin et al., "Time-dependent benefit of initial thrombosuction on myocardial reperfusion in primary percutaneous coronary intervention," International Journal of Clinical Practice, vol. 62, no. 4, pp. 555-561, 2008.

[124] J. Lipiecki, S. Monzy, N. Durel et al., "Effect of thrombus aspiration on infarct size and left ventricular function in high-risk patients with acute myocardial infarction treated by percutaneous coronary intervention. Results of a prospective controlled pilot study," American Heart Journal, vol. 157, no. 3, pp. 583-e1, 2009.

[125] B. Chevalier, M. Gilard, I. Lang et al., "Systematic primary aspiration in acute myocardial percutaneous intervention: a multicentre randomised controlled trial of the export aspiration catheter," EuroIntervention, vol. 4, no. 2, pp. 222-228, 2008.

[126] L. Galiuto, B. Garramone, F. Burzotta et al., "Thrombus aspiration reduces microvascular obstruction after primary coronary intervention: a myocardial contrast echocardiography substudy of the REMEDIA trial," Journal of the American College of Cardiology, vol. 48, no. 7, pp. 1355-1360, 2006.

[127] F. Liistro, S. Grotti, P. Angioli et al., "Impact of thrombus aspiration on myocardial tissue reperfusion and left ventricular functional recovery and remodeling after primary angioplasty," Circulation: Cardiovascular Interventions, vol. 2, no. 5, pp. 376383, 2009.

[128] G. Sardella, M. Mancone, C. Bucciarelli-Ducci et al., "Thrombus aspiration during primary percutaneous coronary intervention improves myocardial reperfusion and reduces infarct size. The EXPIRA (thrombectomy with export catheter in infarct-related artery during primary percutaneous coronary intervention) prospective, randomized trial," Journal of the American College of Cardiology, vol. 53, no. 4, pp. 309-315, 2009.

[129] P. J. Vlaar, T. Svilaas, I. C. van der Horst et al., "Cardiac death and reinfarction after 1 year in the Thrombus Aspiration during Percutaneous coronary intervention in Acute myocardial infarction Study (TAPAS): a 1-year follow-up study," The Lancet, vol. 371, no. 9628, pp. 1915-1920, 2008.

[130] O. Frobert, B. Lagerqvist, G. K. Olivecrona et al., "Thrombus aspiration during ST-segment elevation myocardial infarction," The New England Journal of Medicine, vol. 369, no. 17, pp. 15871597, 2013.

[131] M. De Carlo, G. D. Aquaro, C. Palmieri et al., "A prospective randomized trial of thrombectomy versus no thrombectomy in patients with ST-segment elevation myocardial infarction and thrombus-rich lesions: MUSTELA (MUltidevice Thrombectomy in Acute ST-Segment ELevation Acute Myocardial Infarction) trial," JACC: Cardiovascular Interventions, vol. 5, pp. 1223 1230, 2012.

[132] S. Minha, R. Kornowski, H. Vaknin-Assa et al., "The impact of intracoronary thrombus aspiration on STEMI outcomes," Cardiovascular Revascularization Medicine, vol. 13, pp. 167-171, 2012.

[133] M. De Vita, F. Burzotta, I. Porto et al., “Thrombus aspiration in ST elevation myocardial infarction: comparative efficacy in patients treated early and late after onset of symptoms," Heart, vol. 96, no. 16, pp. 1287-1290, 2010.

[134] Y. Onuma, L. Thuesen, R. J. van Geuns et al., "Randomized study to assess the effect of thrombus aspiration on flow area in patients with ST-elevation myocardial infarction: an optical frequency domain imaging study-TROFI trial," European Heart Journal, vol. 34, pp. 1050-1060, 2013.

[135] S. P. Fojtik and L. S. Kronick, "Cardiovascular innovations: novel mechanical aspiration system to improve thrombus aspiration speed, force, and control," Cardiovascular Revascularization Medicine, vol. 14, no. 3, pp. 160-163, 2013. 


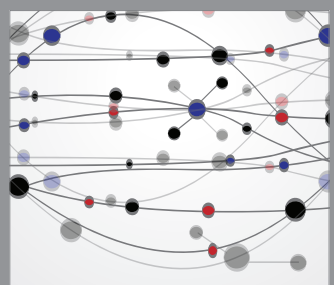

The Scientific World Journal
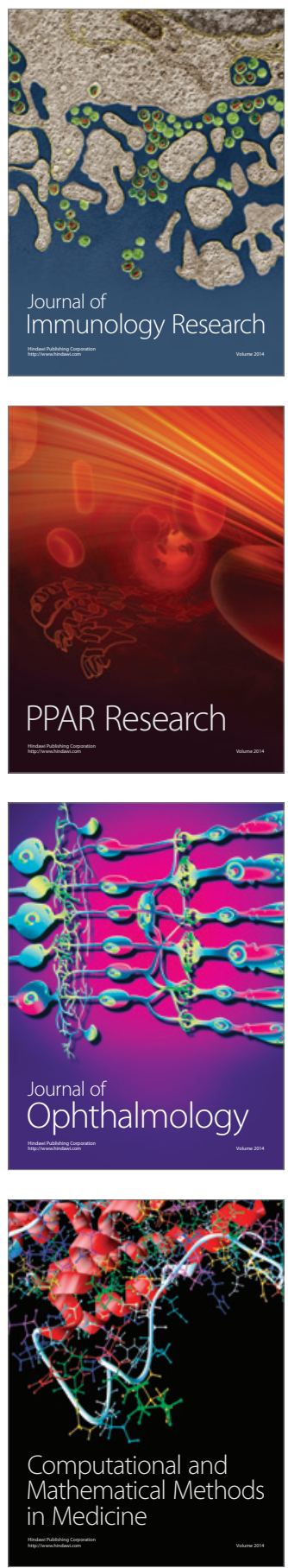

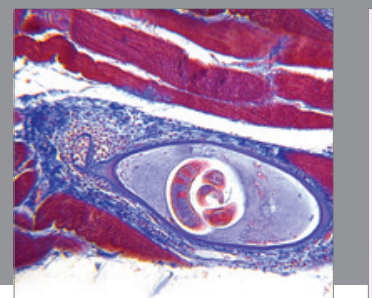

Gastroenterology

Research and Practice
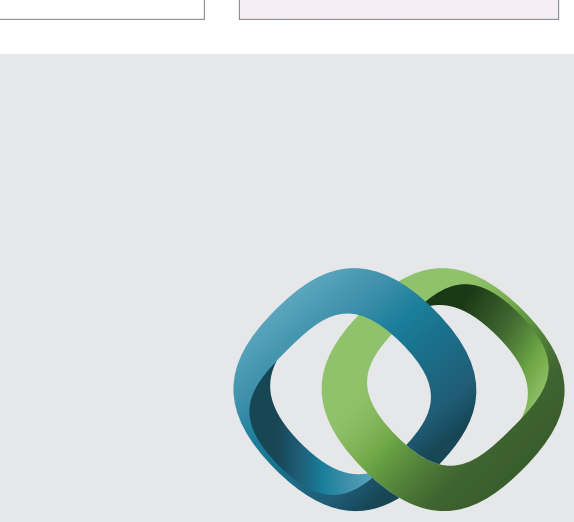

\section{Hindawi}

Submit your manuscripts at

http://www.hindawi.com
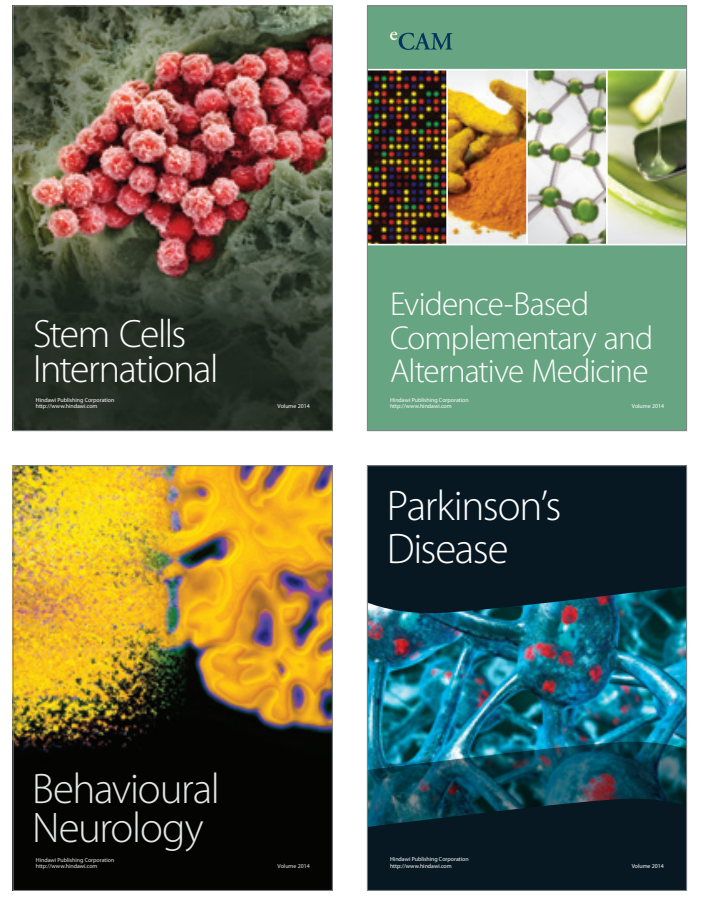
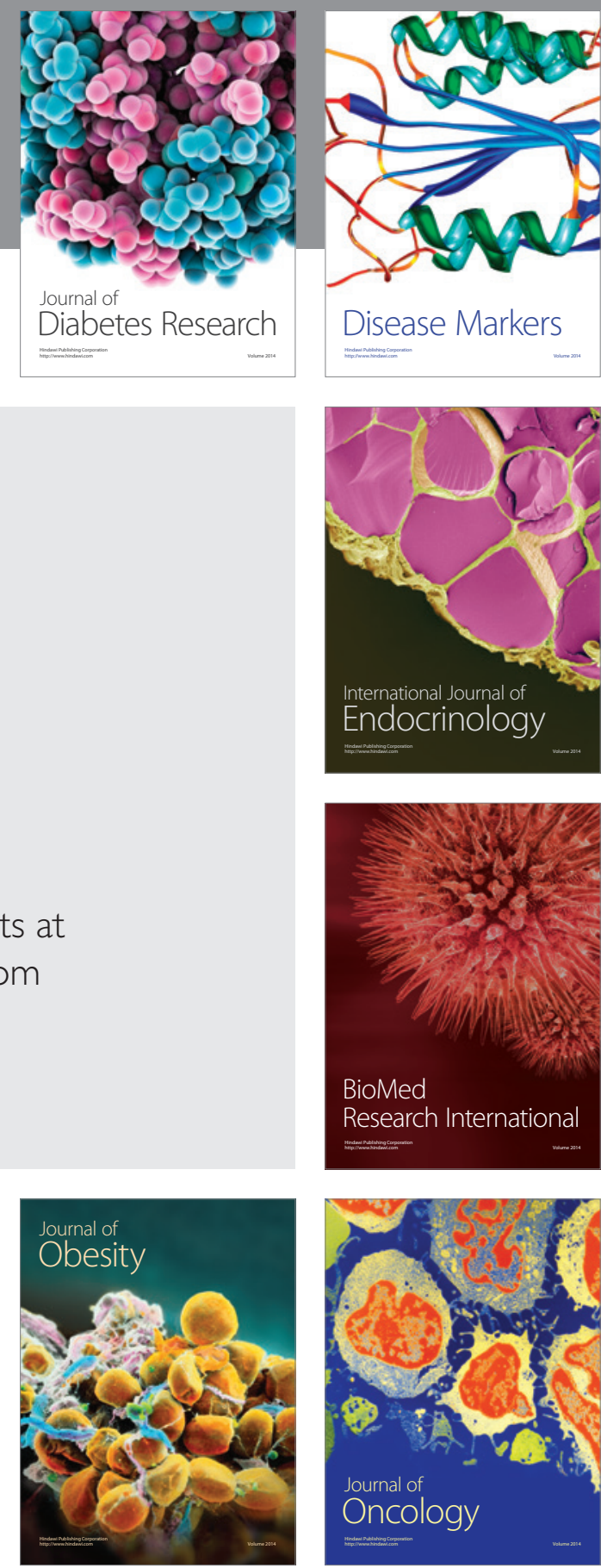

Disease Markers
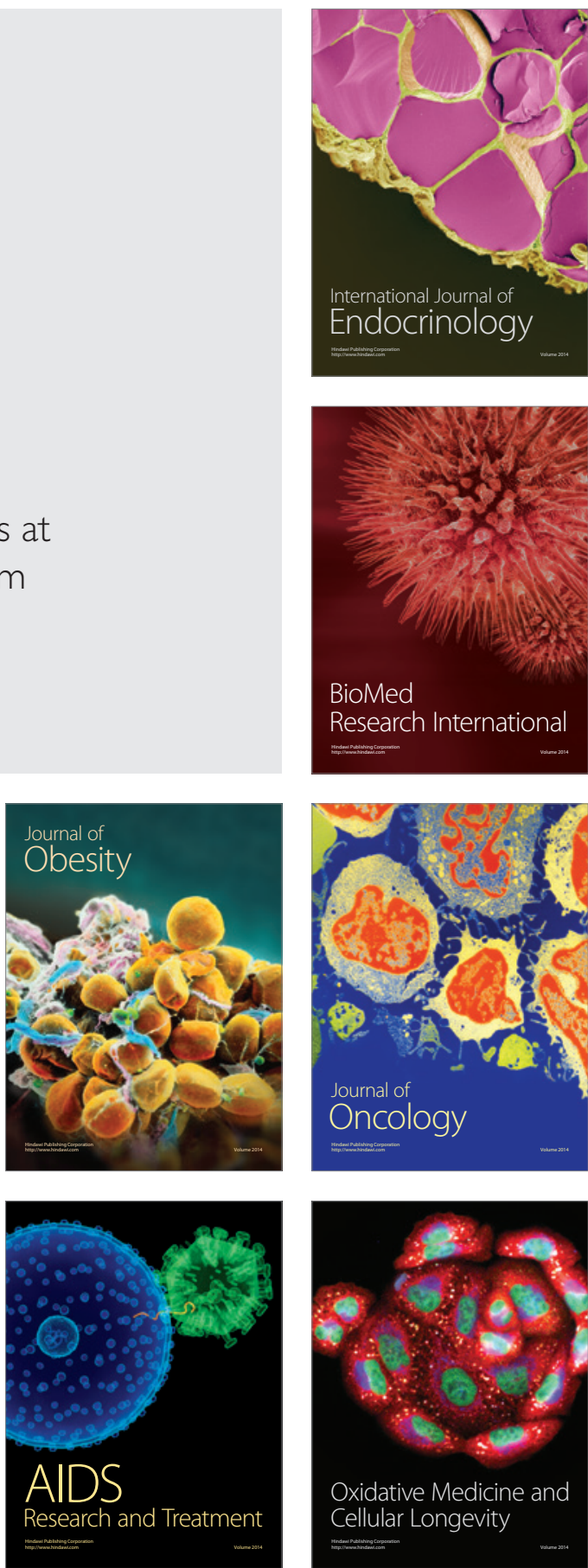